\title{
Health Effects of Intimate Partner Violence against Women: Evidence from Community Based Cross Sectional Study in Western Ethiopia
}

\author{
Sileshi G. Abeya ${ }^{1 *}$, Mesganaw F. Afework ${ }^{2}$ and Alemayeh W. Yalew ${ }^{3}$ \\ ${ }^{1}$ College of Health and Medical Sciences, Departments of Public Health, Wollega University, Ethiopia \\ ${ }^{2}$ Departments of Reproductive Health and Health Management, School of Public Health, \\ Addis Ababa University, Ethiopia \\ ${ }^{3}$ Departments of Epidemiology and Biostatistics School of Public Health, Addis Ababa University, Ethiopia
}

\section{Abstract}

Intimate partner violence against women undermine the physical, mental and reproductive well-being of women. Thus, this study was aimed to assess the association between intimate partner violence against women and a range of adverse health outcomes in East Wollega Zone, West Ethiopia. A cross-sectional population based household survey was conducted between January and April, 2011. A sample of 1540 ever married/cohabited women was chosen using systematic random sampling technique. Standard WHO multicountry study questionnaire was used to interview the selected women. Lifetime experiences of intimate partner violence against women was the independent variable, whereas, the experiences of symptoms of mental distress, physical injury, sexually transmitted infections, unintended and termination of pregnancy were the dependent variables. Data was entered into Epi DATA and analyzed using SPSS 19. Binary logistic regression models were used to predict the association of study variables and adjust for possible confounders. Nearly two third $(64.1 \%)$ of physically abused women had been injured. The vast majority $(94.0 \%)$ experienced symptom of mental distress. Sixty four percent of abused compared to $41.7 \%$ of non-abused women ever had a symptom of sexually transmitted infections $(p<0.001)$. Furthermore, $16 \%$ of abused women had an unintended pregnancy versus $11.3 \%$ reported the same from non-abused women $(p<0.05)$. The results of multiple logistic regression analysis indicated that intimate partner violence against women is independently associated with symptoms of mental distress, sexually transmitted infections, unintended and termination of pregnancy. However, it is not associated with ever use of family planning methods $(p>0.05)$. Intimate partner violence against women negatively affects physical, mental and reproductive health of women in the study areas. This needs an urgent attention by policymakers, stakeholders, and professionals at all levels.
\end{abstract}

Article Information

Article History:

Received : 08-04-2013

Revised : 20-06-2013

Accepted : 22-06-2013

Keywords:

Health outcomes

Intimate partner

Reproductive

Violence against women

Western Ethiopia

${ }^{*}$ Corresponding Author:

Sileshi G. Abeya

E-mail:

garomaabe@yahoo.com

\section{INTRODUCTION}

Intimate partner violence against women (IPVAW) can be defined as a pattern of abuse whereby one partner exerts physical, sexual, or emotional control over a romantic partner (Coker, Smith et al., 2000). IPVAW is one of the most global human rights abuse and public health problems. It is the manifestation of gender inequality for women and girls due to their social status in the society (Kishor and Kiersten, 2004). IPVAW occurs to women of all ages; however, reproductive age represents an increased risk (Kishor and Kiersten, 2004 and Ellsberg, Jansen et al., 2008). Studies elsewhere have indicated that IPVAW undermines the sexual and reproductive, physical and mental well-being of women (Heise, Nahid et al., 1995; Krug et al., 2002; Berhane 2004; Geraldine, 2004).

The health consequences of IPVAW include physical trauma, reproductive health problems, mental/psychological/behavioral problems, and fatal health conditions. Population-based studies have suggested that $20-75 \%$ of intimate partner physical violence against women resulted in injuries (Kishor and Kiersten, 2004) in which abrasion, bruises, 
Sileshi G. Abeya et al.,

fracture, and abdominal thoracic injuries are direct consequences of physical trauma (Gossaye, Deyessa et al., 2003; WHO, 2005; Campbell, 2002). Among the reproductive health problems the most common and frequently cited are highest unmet need for family planning and lower contraceptive use (Kishor and Kiersten, 2004), unintended (unwanted or mistimed) pregnancy (Kishor and Kiersten, 2004; Pallitto Campbell et al., 2005; WHO, 2005), terminated pregnancy (abortion and miscarriages) (Taddesse Yoseph et al., 1994; Janssen Holt et al., 2003 and WHO, 2005), and sexually transmitted infractions (STIs) including HIVIAIDS (Heise Ellsberg et al., 1999; Maman Mbwambo et al., 2000; Kishor and Kiersten, 2004; Dunkle Jewkes et al., 2004; Campbell, 2002). Furthermore, depression, sleeping problems, suicidal ideation and attempts are the most common mental health problems associated with IPVAW (Gossaye Deyessa et al., 2003; WHO, 2005; Deribew, 2007; Campbell, 2002). Among the fatal health problems of IPVAW suicides, homicides, maternal mortality, and AIDS related deaths are common (Krug Dahlberg et al., 2002).

Despite the tremendous consequences, studies focusing on the association between IPVAW and health outcomes are few (Ellsberg and Heise, 2005; Binson et al., 2000), especially in developing countries including Ethiopia (Gossaye Deyessa et al., 2003; WHO, 2005). In the western part of Ethiopia where the culture of the community is fairly different (A National Report, 2004) populationbased study on IPVAW and its consequences is hardly found.

Such information may contribute to the growing literature in the field and may inform policy interventions to manage IPVAW and improve the health condition of women. The study does not necessarily ask new questions, since the reality of a culture of silence around issues of IPVAW has been long acknowledged especially in the context of Reproductive Health (RH) problems of women including HIV and AIDS. It however builds on this acknowledgement by articulating the specific contextual examples and addressing specific issues. Therefore, this study was aimed to fill the gap in assessing the association between IPVAW and a range of non-fatal health outcomes and behaviors in the East Village zone, West Ethiopia.

\section{MATERIALS AND METHODS}

\section{Study Settings}

The study was conducted in one urban and four rural districts in the East Village zone, which is one of the 18 zones of Oromiya regional state. It is located in the western part of the country $331 \mathrm{kms}$
Sci. Technol. Arts Res. J., April-June 2013, 2(2): 48-57

from Addis Ababa, Ethiopia. In the study area, two out of six subcities of Nekemte (the capital city of the zone) and eight out of fifty kebeles of rural settings were randomly selected. The total population of the zone is $1,340,581$ during the study period. Besides, different ethnic groups such as Oromo, Amhara, Gurage and Tigre are residents of the zone, out of which $85 \%$ of the dwellers were Oromo and Afan Oromo is the working language (CSA, 2006 and CSA, 2010). Regarding infrastructure and social services, Nekemte Town has one hospital and two health centers which are government owned, and various private and faithbased health institutions. Similarly, the study woredas have more than one government owned health center each, health posts, infrastructures like telephone services, and dry weather roads. In the study area there are six high schools and 30 primary and junior secondary schools. However, about half of women age $15-49$ years $(51 \%)$ have no formal education and considered illiterate (CSA, 2010). The rural communities are largely dependent on traditional agricultural activity (subsistence farming), whereas the urban population (Nekemte Town) lives off businesses ranging from small to large scale (CSA, 2010).

\section{Study Design and Population}

A comparative cross-sectional population based household survey was carried out between January and April, 2011. As the source population, ever married/cohabited women aged 15-49 years who were residents of the study community for at least 6 months were used. The aforementioned group was selected as it is at the highest risk of intimate partner violence (Garcia, 2006 and Garcia Jansen et al., 2006).

\section{Sample Size Calculation}

Unintended pregnancy was considered as the main outcome of interest and experiencing IPVAW during lifetime as exposure variable. Since the difference in the outcome between exposed and non-exposed is small for unintended pregnancy among the different health outcomes, it gave the maximum sample size to address the objectives. The following assumptions were made to calculate the sample size: $40 \%$ and $29 \%$ of women have the outcome among exposed and non-exposed groups, respectively (Kishor and Kiersten, 2004), a 5\% type I error, $80 \%$ power to detect the assumed differences, a ratio of exposed to non-exposed group of 2:1, a design effect of 2 and adding 10\% for non responses. Accordingly, 506 non-exposed and 1012 exposed women (a total of 1,518) were required for the study. However, as these studies were part of a survey which was conducted to assess the prevalence and risk factors of IPVAW, a 
Sileshi G. Abeya et al.,

larger sample size of 1,600 women was included (Abeya Afework et al., 2011).

To interview the eligible women, multi stage sampling procedure was employed. Firstly, household census and numbering was done in the selected sub-cities and kebeles to obtain a sampling frame. Secondly, after identifying households having the target groups, proportion of sample size allocations were carried out. To this effect, systematic random sampling was used to identify the target from the selected households as a study unit. Only one eligible was selected for interview by Kish grid method to control the potential intrahousehold correlation (Binson Canchola et al., 2000).

\section{Data Collection}

Data were collected by 25 high school completed female interviewers using WHO multi-country study of violence against women (VAW) questionnaire (WHO, 2003). The questionnaire was translated into the local language (Afan Oromo) by experts in both languages and back translated to English by another person to ensure consistency and accuracy. The data collection process was closely supervised by five Health Officers and one of the principal investigators. Enumerators and supervisors were trained for seven consecutive days in sampling, interview techniques and ethical issues, emphasizing the importance of safety of the participants as well as interviewers, minimization of under- reporting and confidentiality. A pre-test was conducted in one kebele out of the study area at $10 \%$ of the total sample size. A standard field work manual developed by the WHO for violence study was adopted and used by all research teams (Ellsberg and Heise, 2005). To ensure the quality of the data and minimize inter-interviewer variation, $\sim 5 \%$ of the respondents were re-interviewed at random by the principal researcher and supervisors and checked for consistency.

\section{Measurements}

The experiences of IPVAW were considered as independent variables and assessed using a modified and revised version of the Conflict Tactic Scale (CTS2) (Straus Hamby et al., 1996). IPVAW is defined as exposure to one or more of physical, sexual or psychological abuse (Garcia Jansen et al., 2006). The details were described in the previous study (Abeya Afework et al., 2011). In addition, variables that have been theoretically, empirically and conceptually linked to health outcomes of IPVAW such as age, education, socioeconomic status (SES), and area of residence were included as independent variables.
Sci. Technol. Arts Res. J., April-June 2013, 2(2): 48-57

Ever experiences of physical injury, unintended (unwanted or mistimed) pregnancy, terminated pregnancies (spontaneous or induced abortion), symptoms of STIs, symptoms of mental distress and ever use of family planning methods were considered as indicators of health outcomes of IPVAW (Krug Dahlberg et al., 2002; Garcia Jansen et al., 2005). In this regards, mental health was assessed by the use of self-reporting questionnaire of 20 questions (SRQ-20), developed by WHO to screen for emotional distress which was validated in many settings (Ellsberg Jansen et al., 2008).

\section{Analysis}

The pre-coded responses were double entered into the Epi- DATA version 3.1 and later it was exported into IBM SPSS statistics 19 for data checking, cleaning, simple and multiple logistic regression analysis. The strengths and directions of the associated factors were explained (reported) using adjusted odds ratios relative to the reference category, at statistical significance of $95 \%$ confidence level and $P$-value of $<0.05$. A separate analysis was done for all health outcomes of IPVAW. The model adequacy and Collinearity assumptions were checked to be satisfied based on appropriate methods designed for the study.

\section{Ethical Considerations}

The research was approved for scientific and ethical integrity by an institutional review board by College of Health Sciences, Addis Ababa University. Moreover, WHO guideline on ethical issues related to violence research was strictly followed (Heise Nahid et al., 1995; Ellsberg Heise et al., 2001; Ellsberg and Heise, 2005). For this reason, all interviews took place in a complete privacy except for children under two years of age. For the respondents aged from 15 to 17 years assent was secured from parents or guardians. During data collection the interviewee with serious psychological distress, happen to be suicide or in need of counseling was referred to Nekemte Hospital. Otherwise, the information about available local services was provided to all respondents. Follow-up services were also provided for some respondents who were in need of help.

\section{RESULTS}

\section{Socio-Demographic Characteristics}

A total of 1540 study subjects completed the interview making a response rate of $96.3 \%$. The socio-demographic characteristics of the women are described in table 1 . The majority $(84.2 \%)$ were residing in a rural setting and most $(78.6 \%)$ of the women were in the age range of $20-34$ years. The mean age of the women was 28.4 years ( \pm 5.7 SD). The vast majority $(98.7 \%)$ was ever married at the 
Sileshi G. Abeya et al.,

time of the interview and predominantly Christian $(97.5 \%)$ and Oromo $(96.4 \%)$ by their religion and ethnicity, respectively.

Nearly about three fifth $(59.7 \%)$ of the women had no formal education. Moreover, more than four in every five women (83.3\%) had no job but manage their own household as their main occupation (housewives) and $59.5 \%$ of the women have moved to the study area after being born and brought up in
Sci. Technol. Arts Res. J., April-June 2013, 2(2): 48-57

other places because of marriage or work related conditions (Table 1).

Overall the prevalence of both lifetime experiences of emotional, physical, and sexual violence was $70.2 \%, 68.6 \%$, and $61.6 \%$ respectively. Of the total respondents, more than three quarters $(76.5 \%)$ reported having had an experience of IPVAW in one form or another at some point in their lifetime, and $72.5 \%$ reported for the same in the preceding year.

Table 1: Socio demographic characteristics of 1540 ever married/cohabited women age 15-49 years in East Wollega Zone, January to April, 2011.

\begin{tabular}{|c|c|c|}
\hline \multirow{2}{*}{\multicolumn{3}{|c|}{$\begin{array}{l}\text { Characteristics (Variables) } \mathrm{n}=1540 \\
\text { Residency }\end{array}$}} \\
\hline & & \\
\hline Urban & 240 & 15.8 \\
\hline Rural & 1296 & 84.2 \\
\hline \multicolumn{3}{|l|}{ Age } \\
\hline $15-19$ years & 28 & 1.8 \\
\hline $20-34$ years & 1,208 & 78.4 \\
\hline 35- 49 years & 304 & 19.8 \\
\hline Mean age & \multicolumn{2}{|c|}{$28.5 \pm 5.7 \mathrm{SD}$} \\
\hline \multicolumn{3}{|l|}{ Religion } \\
\hline Christian & 1496 & 97.5 \\
\hline Muslim & 18 & 1.2 \\
\hline Others (Catholic, others) & 20 & 1.3 \\
\hline \multicolumn{3}{|l|}{ Ethnicity } \\
\hline Oromo & 1484 & 96.4 \\
\hline Amara & 40 & 2.6 \\
\hline Others (Gurage, Tigre) & 16 & 1.0 \\
\hline \multicolumn{3}{|l|}{ Place of birth and grownup } \\
\hline Same community & 624 & 40.5 \\
\hline Different community & 916 & 59.5 \\
\hline \multicolumn{3}{|l|}{ Marital status } \\
\hline Currently married & 1420 & 92.2 \\
\hline Currently cohabited & 20 & 1.3 \\
\hline Separated/divorced/widowed & 100 & 6.5 \\
\hline \multicolumn{3}{|l|}{ Education level } \\
\hline No formal education & 919 & 59.7 \\
\hline Primary (1-6th grade) & 399 & 25.9 \\
\hline Secondary $\left(>=7^{\text {th }}\right.$ grade $)$ & 222 & 14.4 \\
\hline \multicolumn{3}{|l|}{ Current occupation } \\
\hline Student & 12 & 0.8 \\
\hline No job & 1283 & 83.3 \\
\hline Trade activities & 63 & 4.0 \\
\hline Govern. Employee & 24 & 1.6 \\
\hline Farmer/female headed & 74 & 4.8 \\
\hline Others & 84 & 5.5 \\
\hline \multicolumn{3}{|l|}{ Wealth quintile } \\
\hline Very poor & 305 & 19.8 \\
\hline Poor & 320 & 20.8 \\
\hline Medium & 318 & 20.6 \\
\hline Rich & 269 & 17.5 \\
\hline Very rich & 328 & 21.3 \\
\hline Experiences of lifetime emotional violence & 1081 & 70.2 \\
\hline Experiences of lifetime physical violence & 1056 & 68.6 \\
\hline Experiences of lifetime sexual violence & 948 & 61.6 \\
\hline Experiences of lifetime IPVAW & 1178 & 76.5 \\
\hline
\end{tabular}


Sileshi G. Abeya et al.,

\section{Health Problems}

From 1056 (68.6\%) of women who had experienced lifetime physical intimate partner violence, $987(64.1 \%)$ had been injured for at least once in their lifetime. Minor injuries such as scratch, abrasion and bruises are most commonly reported by $60.1 \%$ of the women. About one third (31.5\%) experienced severe forms of physical violence like cuts, punctures and bites. Besides this, women experienced the most severe forms like sprains and dislocations $(22.5 \%)$, burns $(6.8 \%)$, injuries to the
Sci. Technol. Arts Res. J., April-June 2013, 2(2): 48-57

eyes and ears $(5.3 \%)$, fractures $(3.8 \%)$, broken teeth $(1.2 \%)$ and other forms of injuries $(0.3 \%)$ in their lifetime. Due to these events, nearly one third $(28.5 \%)$ of women reported to have ever loss of consciousness from which $104(10.6 \%)$ reported to have lost their consciousness for more than one hour. Although $86(8 \%)$ of them were injured badly enough and needed health care, only $69(6.5 \%)$ of them received health care at least once for their injuries (Table 2).

Table 2: Distribution of physically abused women according to types of injury in the East Wollega Zone, January to April, 2011.

\begin{tabular}{lcc}
\hline \multicolumn{1}{c}{ Variables } & \multicolumn{2}{c}{ During lifetime } \\
\cline { 2 - 3 } & Number & Percent \\
\hline Physical injury (N= 987) & & \\
Cuts, punctures, bites & 485 & 31.5 \\
Scratch, abrasion, bruises & 925 & 60.1 \\
Sprains, dislocations & 346 & 22.5 \\
Burns & 105 & 6.8 \\
Penetrating injury, deep cuts, gashes & 33 & 2.1 \\
Broken eardrum, eye injuries & 81 & 5.3 \\
Fractures, broken bones & 59 & 3.8 \\
Broken teeth & 18 & 1.2 \\
At least one of the above & 987 & 64.1 \\
Ever loss consciousness because of physical violence & & \\
Yes & 280 & 28.4 \\
No & 701 & 71.6 \\
Time of loss of consciousness & 176 & 18.4 \\
Less than 1 hour & 104 & 10.6 \\
More than 1 hour & 701 & 71.6 \\
No & & \\
Need health care n=1074 & 86 & 8.0 \\
Yes & 727 & 67.7 \\
No & & \\
Ever receive health care because of physical violence n=1074 & 69 & 6.4 \\
Yes & 17 & 1.6 \\
No & &
\end{tabular}

The vast majority $(93.3 \%)$ of the women experienced one or more of the 20 symptoms of mental distress in their lifetime. The majority $(82.8 \%)$ had headaches, followed by feelings of nervousness or get worried which accounted for $72.8 \%$. Surprisingly, about one third $(30.8 \%)$ of the women ever thought of ending their life (Table 3).

Regarding the sexually transmitted infections (STI), the result indicated that $64 \%$ of women who have experienced lifetime IPVAW had at least one symptom of STI compared to $42 \%$ of their counterparts. Accordingly, about one third (32.8\%) reported a burning sensation during urination and other symptoms like genital itching and unusual discharge from genitalia that accounted for $26.0 \%$ and $13.4 \%$, respectively (Figure 1 ).
In relation to STI symptoms, nearly one third (31.1\%) of women who experienced IPVAW in their lifetime had perceived risks of contracting HIV and AIDS compared to one quarter $(25 \%)$ of women without such experiences. On the other hand, more than one in every six (16.3\%) women had experienced both IPVAW and unintended pregnancy for at least once in their lifetime than $11.3 \%$ of non-abused women reported for the same. In the same way, the lifetime experiences of terminated pregnancy were reported by $82(7.2 \%)$ of abused women verses $17(4.8 \%)$ for their counterparts. Similar pattern were seen for the mental health problem of the women in the study area (Table 4). 
Table 3: Distribution of women reported symptoms of mental distress based on $20 \mathrm{SRQ}$ in East Wollega Zone, January to April, 2011.

\begin{tabular}{lll}
\hline Life time experiences symptoms of mental distress $\mathbf{( n = 1 5 4 0 )}$ & Number & Percent \\
\hline Head ache & 1275 & 82.8 \\
Poor appetite & 541 & 35.1 \\
Sleep badly & 700 & 45.5 \\
Easily frightened & 622 & 40.4 \\
Hands shake & 354 & 23.0 \\
Feel nervous, tense or worried & 1121 & 72.8 \\
Poor digestion & 486 & 31.6 \\
Trouble thinking & 659 & 42.8 \\
Feel unhappy & 813 & 52.8 \\
Cry more than usual & 910 & 59.1 \\
Difficult to enjoy & 695 & 45.1 \\
Difficult to make decisions & 634 & 41.2 \\
Suffering in daily work & 904 & 58.7 \\
Unable to play & 809 & 52.5 \\
Lost interest in things & 736 & 47.8 \\
Feel worthless person & 809 & 52.5 \\
Thought of ending life & 475 & 30.8 \\
Feel tired & 936 & 60.8 \\
Uncomfortable feelings in stomach & 783 & 50.8 \\
Easily tired & 899 & 58.4 \\
One or more symptoms of mental distress & 1512 & 93.3 \\
\hline
\end{tabular}

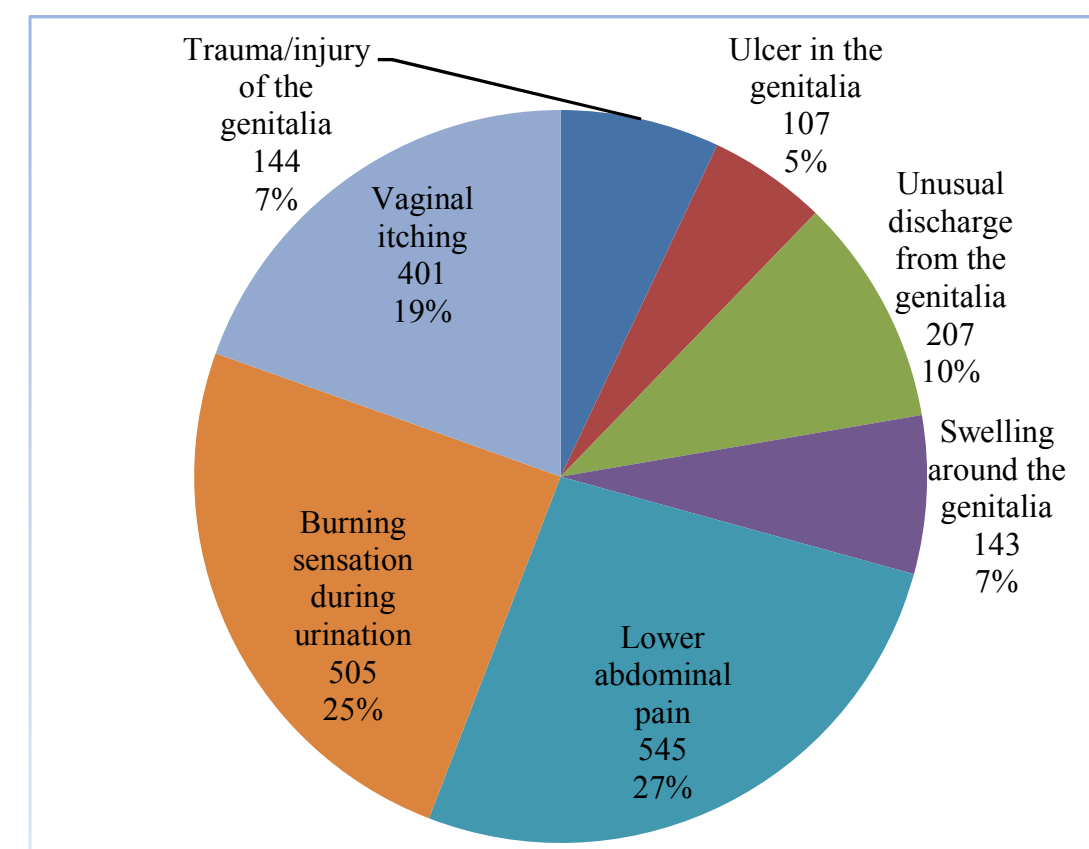

Figure 1: Distribution of women reported lifetime symptoms of sexually transmitted infections in East Wollega Zone, January to April, 2011. 
Sileshi G. Abeya et al.,

\section{Association of Intimate Partner Violence against Women}

The association of IPVAW with mental health problems \& selected reproductive health outcomes/ behavior were assessed independently at bivariate level. In a multiple variable analysis other potential factors such as age of the women, education level, area of residence, and SES were controlled (Emenike Lawoko et al., 2008) and the results of the final models are presented in Table 4.

The results showed that women reported the lifetime experience of sexual violence nearly twice (AOR, 1.71; $95 \% \mathrm{Cl}, 1.15$ to 2.55 ) more likely to have one or more symptoms of mental distress in their lifetime. The association of the symptoms of mental distress was not statistically significant with lifetime experiences of psychological and physical violence. Nevertheless, women experienced at least one of IPVAW are (AOR, 1.40; $95 \% \mathrm{Cl}, 1.10$ to 2.31) more likely to report symptoms of mental distress.

Compared to women who had not experienced any form of IPVAW, those who had the experience were significantly at increased likelihood to have symptoms of STI in their lifetime. Women experienced psychological, physical, sexual, and at least one of IPVAW in their lifetime were more than two times (AOR, 2.79; 95\% Cl, 2.23 to 3.50), (AOR, 2.68; $95 \% \mathrm{Cl}, 2.14$ to 3.35), (AOR, 2.18; 95\% Cl, 1.76 to 2.70 ), and (AOR, 2.46; $95 \% \mathrm{Cl}, 1.93$ to 3.14 ) as likely to have at least one symptoms of STI in their lifetime, respectively. Moreover, women experienced IPVAW had increased odds of reporting perceived risks of contracting HIV and AIDS than their counterparts. This is to mean that, women who had experienced physical violence (AOR, 1.31; 95\% Cl, 1.01 to 1.69), sexual violence (AOR, 1.39; 95\% Cl, 1.09 to 1.77 ), and IPVAW (AOR, 1.35; 95\% Cl, 1.02 to 1.78 ) were more likely to perceive the risk of catching HIV and AIDS than their counterparts.

In this study, none of the different forms of IPVAW were statistically associated with ever use of family planning. In spite of this, women experienced psychological violence (AOR, 1.44; 95\% Cl, 1.04 to 1.99), physical violence (AOR, $1.49 ; 95 \% \mathrm{Cl}, 1.07$ to 2.05 ), sexual violence (AOR, $1.63 ; 95 \% \mathrm{Cl}, 1.20$ to 2.22), and at least one IPVAW (AOR, 1.46; $95 \% \mathrm{CI}$, 1.01 to 2.09) in their lifetime were more likely to have an unintended pregnancy. In addition, women experienced lifetime physical violence (AOR, 1.79; $95 \% \mathrm{Cl}, 1.08$ to 2.97 ) and at least one IPVAW (AOR, 1.79; 95\% Cl, 1.02 to 3.15) were more likely to have terminated pregnancy in one form or another than their counterparts (Table 4).
Sci. Technol. Arts Res. J., April-June 2013, 2(2): 48-57

\section{DISCUSSION}

The main findings of this study are more than half $(60 \%)$ of women have no formal educations and IPVAW is the most prevalent in the study area. Moreover, IPVAW is independently associated with negative effects on women's health.

The experiences of physical injuries in this study are consistent with those of the studies elsewhere that established physical intimate partner violence as common causes of injury to women (Kishor and Kiersten, 2004; Krug Dahlberg et al., 2002; Ellsberg Jansen et al., 2008). In addition, in this study more than a quarter $(28.4 \%)$ of women experienced loss of consciousness due to physical violence at least once in their lifetime. This corroborates findings from Butajira that showed $26.7 \%$ of women experienced loss of consciousness for the same reason (Ellsberg Jansen et al., 2008). This indicates that the severity of physical violence is alarming for women's health and warrants other studies to assess death of women associated with physical IPVAW.

Moreover, the odds of ever having one or more symptoms of self reported mental health problem were significantly higher among women who reported sexual violence and at least one form of IPVAW than women who did not. This coincides with studies from other countries (Heise Ellsberg et al., 1999; Krug Dahlberg et al., 2002). This might imply that IPVAW in general and sexual violence in particular possibly results in poor mental health, suicidal ideation and attempts.

The use of family planning is not statistically associated with all forms of IPVAW. This is in contrast with the findings of studies from other countries (Kishor and Kiersten, 2004; Emenike Lawoko et al., 2008) and particularly Colombia, where IPVAW was associated with restricted use of family planning methods (Pallitto and O'Campo, 2004). The difference is possibly due to cultural variations in men's attitudes towards women's use of contraceptives in different societies (Emenike Lawoko et al., 2008). This is best explained by the fact that the use of contraceptives is more likely to be accepted in more liberal societies than in conservative societies where using family planning out of the knowledge of husbands/partners may not be regarded as a social norm.

Although this study did not collect data on current HIV and AIDS status of the women, it showed that about one out of every three women perceived HIV as a possible consequence of experiences of IPVAW. This is consistent with the study result that showed increasing links between IPVAW and HIV (UNAIDS, 2008). Further, it has been found out that 
Table 4: Proportion of violence and Odds ratios $(95 \% \mathrm{Cl})$ from binary logistic regressions assessing the association of mental problem and selected reproductive health outcomes and behaviors of IPVAW among 1540 ever married/cohabited women age 15-49 years in East Wollega Zone, January to April, 2011.

\begin{tabular}{|c|c|c|c|c|c|c|c|c|c|}
\hline \multirow{2}{*}{$\begin{array}{l}\text { Forms of } \\
\text { PVAW in } \\
\text { lifetime } \\
(n=1540)\end{array}$} & \multicolumn{3}{|c|}{ Mental Health Problems } & \multicolumn{3}{|c|}{ Symptoms of STI } & \multicolumn{3}{|c|}{ Perceived Risk of HIVIAIDS } \\
\hline & No $(\%)$ & Yes (\%) & AOR $(95 \% \mathrm{Cl})$ & No $(\%)$ & Yes (\%) & AOR $(95 \% \mathrm{Cl})$ & No (\%) & Yes (\%) & AOR $(95 \% \mathrm{Cl})$ \\
\hline \multicolumn{10}{|l|}{$\begin{array}{l}\text { Emotional } \\
\text { Violence }\end{array}$} \\
\hline No & $39(8.5) \quad 4$ & $418(91.5)$ & 1.00 (Reference) & $268(58.6)$ & $189(41.4)$ & 1.00 (Reference) & $328(74.1)$ & $111(25.3)$ & 1.00 (Reference) \\
\hline Yes & $64(5.9) \quad 1$ & $1019(94.1)$ & $0.99(0.78,1.25)$ & 367 (33.9) & $716(66.1$ & $2.79(2.23,3.50)^{\star *}$ & $712(68.50$ & 327 (31.5) & $1.24(0.95,1.61)$ \\
\hline \multicolumn{10}{|l|}{$\begin{array}{l}\text { Physical } \\
\text { Violence }\end{array}$} \\
\hline No & $36(7.7) \quad 4$ & $430(92.3)$ & 1.00 (Reference) & $269(57.7)$ & $197(42.3)$ & 1.00 (Reference) & $332(74.1)$ & $116(25.90$ & 1.00 (Reference) \\
\hline Yes & $67(6.2) \quad 1$ & $1007(93.8)$ & $1.13(0.90,143)$ & $366(34.1)$ & $708(65.9)$ & $2.68(2.14,3.35)^{\star *}$ & $638(67.9)$ & $322(31.3)$ & $1.31(1.01,1.69)^{*}$ \\
\hline \multicolumn{10}{|l|}{$\begin{array}{l}\text { Sexual } \\
\text { Violence }\end{array}$} \\
\hline No & $49(8.8) \quad 5$ & $506(91.2)$ & 1.00 (Reference) & $290(52.3)$ & $265(47.7)$ & 1.00 (Reference) & $402(74.7)$ & $136(25.3)$ & 1.00 (Reference) \\
\hline Yes & $54(5.5)$ & $931(94.5)$ & $0.93(0.75,1.16)$ & $345(35.0)$ & $640(65.0)$ & $2.18(1.76,2.70)^{\star *}$ & $638(67.9)$ & $302(32.1)$ & $1.39(1.09,1.77)^{*}$ \\
\hline \multicolumn{10}{|l|}{ One or } \\
\hline IPVAW & $32(8.8)$ & $330(91.2)$ & 1.00 (Reference) & $211(58.3)$ & $151(41.7)$ & 1.00 (Reference) & $262(75.1)$ & $87(24.9)$ & 1.00 (Reference) \\
\hline $\begin{array}{l}\text { No } \\
\text { Yes }\end{array}$ & $71(6.0) \quad 1$ & $1107(94.0)$ & $1.14(0.89,1.47)$ & $424(36.0)$ & $754(64.0)$ & $2.46(1.93,3.14)^{\star *}$ & 778 (68.9) & $351(31.1)$ & $1.35(1.02,1.78)^{*}$ \\
\hline \multicolumn{10}{|c|}{$\begin{array}{l}\text { STI- Sexually transmitted infections, }{ }^{*} p \text { - Value }<0.05,{ }^{* *} p \text {-Value }<0.001 \text {, Adjusted for age of the women, education level, area of residence, and } \\
\text { SES }\end{array}$} \\
\hline \multirow{2}{*}{$\begin{array}{l}\text { Forms of } \\
\text { PVAW in } \\
\text { lifetime } \\
(n=1540)\end{array}$} & \multicolumn{3}{|c|}{ Use of Family Planning } & \multicolumn{3}{|c|}{ Unintended Pregnancy † } & \multicolumn{3}{|c|}{ Terminated Pregnancy § } \\
\hline & No $(\%)$ & Yes (\%) & AOR $(95 \% \mathrm{CI})$ & No $(\%)$ & Yes (\%) & AOR $(95 \% \mathrm{CI})$ & No (\%) & Yes(\%) & AOR $(95 \% \mathrm{Cl})$ \\
\hline \multicolumn{10}{|l|}{$\begin{array}{l}\text { Emotional } \\
\text { Violence }\end{array}$} \\
\hline No & $195(42.7)$ & $262(57.3)$ & 1.00 (Reference) & $402(88.0)$ & $55(12.0)$ & 1.00 (Reference) & $427(94.7)$ & $24(5.3)$ & 1.00 (Reference) \\
\hline Yes & $450(41.6)$ & $633(58.4)$ & $0.99(0.78,1.25)$ & $905(83.6)$ & $178(16.4)$ & $1.44(1.04,1.99)^{*}$ & $976(92.4)$ & $75(7.1)$ & $1.45(0.90,2.34)$ \\
\hline \multicolumn{10}{|l|}{$\begin{array}{l}\text { Physical } \\
\text { Violence }\end{array}$} \\
\hline No & $198(42.5)$ & $268(57.5)$ & 1.00 (Reference) & 411 (88.2) & $55(11.8)$ & 1.00 (Reference) & $463(95.2)$ & $22(5.3)$ & 1.00 (Reference) \\
\hline Yes & $447(41.6)$ & $627(58.4)$ & $1.13(0.90,143)$ & $896(83.4)$ & $178(16.6)$ & $1.49(1.07,2.05)^{*}$ & 967 (92.6) & $75(7.1)$ & $1.79(1.08,2.97)^{*}$ \\
\hline \multicolumn{10}{|l|}{$\begin{array}{l}\text { Sexual } \\
\text { Violence }\end{array}$} \\
\hline No & $223(40.2)$ & $332(59.8)$ & 1.00 (Reference) & 492 (88.6) & $63(11.4)$ & 1.00 (Reference) & $515(94.3)$ & $31(5.7)$ & 1.00 (Reference) \\
\hline Yes & $422(42.8)$ & $563(57.2)$ & $0.93(0.75,1.16)$ & $815(82.7)$ & $170(17.3)$ & $1.63(1.20,2.22)^{*}$ & 888 (92.9) & $68(7.1)$ & $1.41(0.90,2.20)$ \\
\hline \multicolumn{10}{|l|}{$\begin{array}{l}\text { One or } \\
\text { more of }\end{array}$} \\
\hline IPVAW & $164(45.3)$ & $198(54.7)$ & 1.00 (Reference) & $321(88.7)$ & $41(11.3)$ & 1.00 (Reference) & 339 (95.2) & $17(4.8)$ & 1.00 (Reference) \\
\hline $\begin{array}{l}\text { No } \\
\text { Yes }\end{array}$ & $481(40.8)$ & $697(59.2)$ & $1.14(0.89,1.47)$ & 986 (83.7) & $192(16.3)$ & $1.46(1.01,2.09)^{*}$ & $1064(92.8)$ & $82(7.2)$ & $1.79(1.02,3.15)^{*}$ \\
\hline
\end{tabular}

all forms of IPVAW are significantly and consistently associated with women lifetime report of STIs and this corroborates findings from other studies (Kishor and Kiersten, 2004; Campbell, 2002). The explanation seems to be lack of sexual autonomy among women who experienced IPVAW as this might predispose them to different reproductive health problems such as STIs, HIV and AIDS, and unintended pregnancy with its consequences.

In the same way, women who experienced all forms of IPVAW are at increased odds of having an unintended pregnancy than their counterparts. This is consistent with the results from Uganda in which women experienced IPVAW had more unintended pregnancies after adjusting for age, pregnancy intention and marital status (Kaye Mirembe et al., 2006). In addition, the demographic health survey finding in Cambodia showed that $60 \%$ of women who have ever experienced IPVAW had intended pregnancy at the time of birth compared to $71 \%$ of women who have never experienced IPVAW (Kishor and Kiersten, 2004). The plausible explanation could be the lack of sexual autonomy among abused women suggests a greater risk of having a mistimed as well as an unwanted pregnancy and birth.

Women who had experienced IPVAW in their lifetime had greater odds of having terminated 
Sileshi G. Abeya et al.,

pregnancy. This is consistent with other studies (Taddesse Yoseph et al., 1994; Janssen Holt et al., 2003; Garcia Jansen et al., 2005; Emenike Lawoko et al., 2008). It is possible to explain that in most developing countries, unintended pregnancy ends up with induced abortion. This could be a manifestation of emotional withdrawal and loss of hope because of IPVAW in being able to care for the eventual newborn child.

In general, at least two plausible mechanisms have been put forward to explain the potential association between IPVAW (especially physical or sexual violence) and adverse reproductive health outcomes. One mechanism is the direct biological effects of coerced intercourse such as unintended pregnancy, termination of pregnancy, STIs and their consequences. The second mechanism suggests that physical or sexual violence may dis-empower women in negotiating safer sex and may negatively affect protective behaviors related to fertility regulation and STIs (Erulkar, 2004).

Though it has come up with useful information, this study has the following limitations. The crosssectional nature of the study may cause difficulty of determining the direction of the association between study variables and the association can only be discussed in terms of plausibility. Social desirability bias may have some impact on the response to some sensitive questions like self reported STIs though syndromic assessment would have been better.

\section{CONCLUSION}

Intimate partner violence against women is a major public health problem in the study community. Moreover, women that experienced IPVAW suffered from negative physical health consequences including injury to the body and loss of consciousness. IPVAW is also seen to contribute to poor mental health and negative reproductive health and behaviors including perceived risks of HIVIAIDS, Sexually transmitted infections, unintended pregnancy and termination of pregnancy.

This clearly indicated that the victims of IPVAW need not only treatment of physical injuries but also counselling, and support (psychological, material) to enable them to cope with the violence and the emotional turmoil. The counselling could be regarded decision-making about health care or leaving the relationship. This needs an urgent attention at all levels of societal organization including policy makers, stakeholders, and professionals. Moreover, extensive and longitudinal research is needed to explore more.
Sci. Technol. Arts Res. J., April-June 2013, 2(2): 48-57

\section{ACKNOWLEDGEMENTS}

We are very much grateful to Addis Ababa University and Bill and Melinda Gates Institute, John Hopkins University for funding the study. Our thanks also go to the study participants for their willingness to participate in the research.

\section{REFERENCES}

A National Report (2004). Progress made in the Implementation of the Beijing Platform for Action Beijing + 10) Ethiopia, Prime Minister Office/Women's Affairs Sub Sector.

Abeya, S.G., Afework, M.F., Yalew, A.W. (2011). Intimate partner violence against women in western Ethiopia: prevalence, patterns, and associated factors. BMC Public Health 11: 913.

Berhane, Y. (2004). Ending Domestic violence against women in Ethiopia. Ethiopia Journal of Health Development 18(3): 131- 132.

Binson, D., Canchola., Catania, J. (2000). Random selection in a telephone survey: A comparison of the kish, next-birthday, and last-birthday methods. Journal of Official Statistics 16: 53-59.

Campbell, J. (2002). Health consequences of intimate partner violence." Lancet 359(9314): 1331-1336.

Coker, A., Smith, P., McKeown, R., King, M. (2000). Frequency and correlates of intimate partner violence by type: Physical, sexual, and psychological battering. American Journal of Public Health 90(4): 553-559.

CSA (2006). Central Statistical Agency [Ethiopia] and ORC Macro. Ethiopia Demographic and Health Survey 2005. Addis Ababa, Ethiopia and Calverton, Maryland, USA: Central Statistical Agency and ORC Macro.

CSA (2010). Statistical Abstract of Federal Democratic Republic of Ethiopia, CSA, December 2010. Addis Ababa, Ethiopia.

Deribew, A. ( 2007). The mental health consequences of Intimate Partner violence against women, Agaro town southwest Ethiopia, Ethiopian Public Health Associations $\mathrm{XVIII}{ }^{\mathrm{TH}}$ Annual public health conference : pp 20- 21.

Dunkle, K., Jewkes, R., Brown, H., Yoshihama, M., Gray G., Mclntyre, J. (2004). Gender Based Power, Relationship power and risk of HIV in women attending antenatal clinic in South Africa. Lancet 363(9419): 1415-1421.

Ellsberg, M. and Heise, L. (2005). Researching Violence against Women: A Practical Guide for Researchers and Activists. Washington DC, United States: World Health Organization, PATH.

Ellsberg, M. and Heise, L. (2001). Researching domestic violence against women: Methodological and ethical considerations. Studies in Family Planning 32(1): 116. 
Sileshi G. Abeya et al.,

Ellsberg, M., Heise, L., Pena, R., Agurto, S., Winkvist, A. (2008). Intimate partner violence and women's physical and mental health in the WHO multi-country study on women's health and domestic violence: an observational study. Lancet 371: 1165-72.

Ellsberg, M., Jansen, H., Heise, H., Watts, C., García, C. (2008). Intimate partner violence and reproductive health of women in Kenya. International Nursing Review. 55: 97-102.

Erulkar, S. (2004). The Experience of Sexual Coercion Among Young People in Kenya. International Family Planning Perspectives 30(4): 182-189.

Garcia, M., Jansen, H., Ellsberg, M., Heise, L., Watts, C. (2006). Prevalence of intimate partner violence: Findings from the WHO multi country study on women's health and domestic violence. Lancet 368: 1260-1269.

Garcia, M., Jansen, H., Ellsberg, M., Watts, C. (2005). WHO multi-country study on women's health and domestic violence against women: initial results on prevalence, health outcomes and women's response. Geneva: World Health Organization.

Geraldine, T. (2004). Poverty reduction and violence against women: exploring links, assessing impact. Development in Practice 14(4).

Gossaye, Y., Deyessa, N., Berhane, Y. (2003). Butajira Rural Health Program: Womens life events study in rural Ethiopia. Ethiopian Journal of Health Development (Second suppl): 1- 51.

Heise, L., Ellsberg, M. et al., Ending Violence Against Women. Baltimore: John's Hopkins University School of Public Health; Population Information Program; 1999. Report No.: Series L, No. 11.

Heise, L., Ellsberg, M., Gottemoeller, M. (1995). Sexual Coercion and Reproductive Health: A Focus on Research. New York, Population Council.

Janssen, P.A., Holt, V.L. (2003). Intimate partner violence and adverse pregnancy outcomes: A populationbased study. American Journal of Obstetrics and Gynecology 188(5): 1341-1347.

Kaye, D., Mirembe, F., Bantebya, G., Johansson, A., Ekstrom, A. (2006). Domestic violence as risk factor for unwanted pregnancy and induced abortion in Mulago Hospital, Kampala, Uganda. Tropical Medicine and International Health 2(1): 90-101.
Sci. Technol. Arts Res. J., April-June 2013, 2(2): 48-57

Kishor, S. and Kiersten J. (2004 ). Profiling Domestic Violence -A Multi-Country Study. Calverton, Maryland: ORC Macro.

Krug, E., Dahlberg, L., Mercy, J., Zwi, A., Lozano, R. (2002). "The world reports on violence and health. Lancet 360 (9339): 1083- 1088.

Maman, S., Mbwambo, J. (2000). HIV and Violence: Implications for Voluntary Counseling and Testing in Dares Salaam, Tanzania (Washington, DC: Horizons Project/ICRW: 2000): 35.

Pallitto, C., Campbell, C., Patricia, O. (2005). Is Intimate Partner Violence Associated with Unintended Pregnancy? A Review of the Literature. Trauma Violence Abuse 6(217).

Pallitto, C. and O'Campo, P. (2004). The relationship between intimate partner violence and unintended pregnancy: analysis of a national sample from Colombia. International Family Planning Perspective 30 (4): 165-173.

Straus, M., Hamby, S., Boney-McCoy, S., Sugarman, D. (1996). The revised Conflict Tactics Scales (CTS2): Development and preliminary psychometric data. Journal of Family Issues 17: 283-316.

Taddesse, E., Yoseph, S., Gossa, A. (1994). Illegal Abortion at five hospitals in Addis Ababa (Abstract 38). Ethiopian Medical Journal 32: 283- 84.

UNAIDS (2008). Global Coalition on Women and AIDS, background paper on "Violence against women and AIDS".Available from: <http://data.unaids.org /GCWA/ GCWA_BG_Violence_en.pdf> [Accessed 11 march 2008].

WHO (2003). The WHO Multi-Country Study on Women's Health and Domestic Violence: Notes on Use of the Questionnaire (Version 10, 20 september 2003).

WHO (2005). WHO multi-country study on women's health and domestic violence against women: initial results on prevalence, health outcomes and women's responses. Geneva, Switzerland.

World Health Organization. (2003), Violence against Women, Fact Sheet No. 239.

WHO (2002). Available from: <http://www.who.int/ violence_injury_prevention/violence/world_report/en /full_en.pdf $>$. [Accessed 10 June 2008]. 